\title{
Impact and prevention of severe exacerbations of COPD: a review of the evidence
}

\author{
This article was published in the following Dove Press journal: \\ International Journal of COPD \\ 5 October 2017 \\ Number of times this article has been viewed
}

\section{David MG Halpin' \\ Marc Miravitlles ${ }^{2}$ \\ Norbert Metzdorf ${ }^{3}$ \\ Bartolomé Celli ${ }^{4}$}

'Department of Respiratory Medicine, Royal Devon and Exeter Hospital, Exeter, UK; ' 2 Pneumology Department, Hospital Universitari Vall d'Hebron, CIBER de Enfermedades Respiratorias (CIBERES), Barcelona, Spain; ${ }^{3}$ Respiratory Medicine, Boehringer Ingelheim Pharma GmBH \& Co KG, Ingelheim am Rhein, Germany; ${ }^{4}$ Pulmonary Division, Brigham and Women's Hospital, Boston, MA, USA
Correspondence: David MG Halpin Department of Respiratory Medicine, Royal Devon and Exeter Hospital, Barrack Road, Exeter,

Devon EX2 5DW, UK

Tel +44 I392 402 I33

$\mathrm{Fax}+441392402828$

Email d.halpin@nhs.net

\begin{abstract}
Severe exacerbations of COPD, ie, those leading to hospitalization, have profound clinical implications for patients and significant economic consequences for society. The prevalence and burden of severe COPD exacerbations remain high, despite recognition of the importance of exacerbation prevention and the availability of new treatment options. Severe COPD exacerbations are associated with high mortality, have negative impact on quality of life, are linked to cardiovascular complications, and are a significant burden on the health-care system. This review identified risk factors that contribute to the development of severe exacerbations, treatment options (bronchodilators, antibiotics, corticosteroids [CSs], oxygen therapy, and ventilator support) to manage severe exacerbations, and strategies to prevent readmission to hospital. Risk factors that are amenable to change have been highlighted. A number of bronchodilators have demonstrated successful reduction in risk of severe exacerbations, including long-acting muscarinic antagonist or long-acting $\beta_{2}$-agonist mono- or combination therapies, in addition to vaccination, mucolytic and antibiotic therapy, and nonpharmacological interventions, such as pulmonary rehabilitation. Recognition of the importance of severe exacerbations is an essential step in improving outcomes for patients with COPD. Evidence-based approaches to prevent and manage severe exacerbations should be implemented as part of targeted strategies for disease management.
\end{abstract}

Keywords: severe COPD exacerbations, hospitalization, prevention, treatment, bronchodilators, long-acting muscarinic antagonist

\section{Introduction}

Exacerbations of COPD are important events in the course of the disease that have profound impact on patients' health status, functional capacity, and lung function. ${ }^{1,2}$ The severity of exacerbations varies, and the clinical definition of a severe exacerbation is not always uniform; for practical reasons, clinical trials and epidemiological studies normally define severe exacerbations as those resulting in hospitalization. ${ }^{3}$ Severe exacerbations have a particularly significant clinical and socioeconomic impact. A recent database review of $>73,000$ patients found that fewer than half of patients hospitalized for an exacerbation survived for a further 5 years. ${ }^{4}$ Patients who survive severe exacerbations are likely to experience significantly impaired quality of life (QoL), are at increased risk of further exacerbations, ${ }^{5,6}$ and represent a major contributor to the overall health-care costs associated with COPD. ${ }^{7,8}$ Therefore, understanding the factors that lead to an exacerbation being so severe that treatment in hospital is needed, and optimization of patient management to reduce the risk of severe exacerbations, are crucial therapeutic goals for patients with stable COPD.

Currently, the prevalence and burden of severe exacerbations remain high,, 10 despite advances in COPD therapies and increased recognition of the importance 
of preventing exacerbations. This manuscript reviews the risk factors, consequences, and treatment of severe COPD exacerbations, and highlights opportunities to improve the management and prevention of these serious events.

\section{What constitutes a severe exacerbation?}

An exacerbation is typically considered an acute episode characterized by worsening of the patient's respiratory symptoms (ie, baseline dyspnea, cough, and/or sputum production) that is sufficient to require additional therapy. ${ }^{11,12}$ The American Thoracic Society (ATS)/European Respiratory Society (ERS) guidelines classify any exacerbation that can be managed at home (mild or moderate) as level I, while severe exacerbations are stratified further as those requiring hospitalization (level II) and those leading to respiratory failure (level III). ${ }^{12}$ For the purposes of this review, severe exacerbations refers to exacerbations requiring hospitalization, accepting that exacerbations requiring hospitalization may be quite varied in terms of the severity of respiratory symptoms and will also reflect the underlying severity of the patient's lung impairment. In patients with very limited respiratory reserves, less severe exacerbation events may still require hospitalization for effective management. Additional factors that contribute to the decision to admit a patient to hospital include the presence of such comorbidities as heart failure, cardiac arrhythmia, or pneumonia, or the onset of other clinical signs, such as central cyanosis or peripheral edema. ${ }^{11,12}$ Patients may go into hospital as an acute emergency admission or be admitted only after outpatient management of an exacerbation has failed to produce an adequate response. Psychosocial factors may also be involved: the patient's ability to cope at home, which may be a product of their age, mental status, and the level of support they have available to them, is an important consideration in deciding whether they should be treated for an exacerbation as an inpatient or outpatient. ${ }^{11-13}$ Finally, regional differences in local health-care practices and access to health-care services also influence the threshold that determines hospitalization for patients with COPD suffering an exacerbation of COPD. ${ }^{14}$

\section{What are the likely clinical outcomes of severe COPD exacerbations?}

Severe COPD exacerbations have short- and long-term clinical implications, including accelerated loss of lung function, increased mortality, decreased health status, cardiovascular comorbidity, and increased health-care costs..$^{7,15,16}$
An exacerbation has a significant effect on clinical and patientcentered outcomes, including obstruction, dyspnea, and exercise capacity. Patients take a long time to recover from these effects, and may never return to their preexacerbation state. ${ }^{17}$

\section{Impact on mortality}

Hospitalization for COPD exacerbations is associated with a high mortality rate. In an EU COPD audit, 5\% of patients admitted to hospital with a COPD exacerbation died while in hospital. ${ }^{10}$ Consistent with this finding, a recent database review of $>73,000$ patients with up to 17 years' follow-up found that mortality peaked in the first week and remained high during the first 3 months following hospital admission. ${ }^{4}$ Fewer than half of patients hospitalized for an exacerbation were still alive after 5 years' follow-up in this study. ${ }^{4}$ This is consistent with previous reports of $>50 \%$ mortality at 5 years following hospitalization for acute exacerbations of COPD. ${ }^{18,19}$ Long-term posthospitalization mortality rates reported in the literature are quite variable: $12 \%-33 \%$ after 1 year, ${ }^{18-22} 26 \%-39 \%$ after 2 years, ${ }^{18,21,22} 39 \%-49 \%$ after 3 years, ${ }^{18,21,22}$ and $45 \%-47 \%$ after 4 years. ${ }^{18,22}$ It has been suggested that survival following hospitalization for COPD is improving. ${ }^{23}$ However, mortality associated with COPD may be underestimated, as it is often cited as a contributory, rather than underlying, cause of death, or omitted from death certificates altogether if death is primarily attributed to comorbid conditions. ${ }^{24}$ The contribution of nonhospitalized exacerbations to mortality rates (ie, unreported exacerbations that should have warranted hospital treatment) has not been well quantified. ${ }^{25}$ Mortality risk increases with each new exacerbation: there is a fivefold greater risk of mortality after the tenth hospitalization compared with the first (Figure 1). ${ }^{4}$

Identified risk factors for mortality associated with severe exacerbation include older age, male sex, prior hospitalizations, weight loss/low body-mass index, poor QoL, physiological parameters (eg, partial pressure of carbon dioxide $\left.\left[\mathrm{PaCO}_{2}\right]\right)$, pulmonary hypertension, lung cancer, cardiovascular comorbidity, and need for long-term oxygen therapy at discharge. ${ }^{4,69,18,19,22,26-28}$

\section{Health-related quality of life}

Health-related QoL deteriorates in patients experiencing exacerbations; the more frequent and severe the exacerbation, the more rapid and pronounced the decline. ${ }^{29-31}$ Severe exacerbations lead to impairment of the ability to perform usual activities and reduce work productivity. Activity limitation and reduced work productivity have been found to be strongly correlated with the total number of severe exacerbations in 


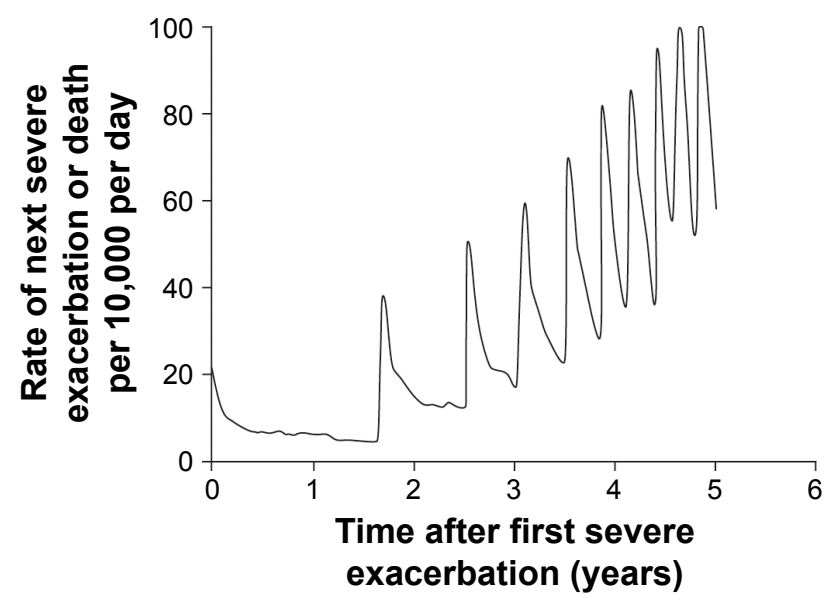

Figure I Hazard function of successive hospitalized COPD exacerbations (per 10,000 per day) for a cohort of 73, 106 patients from the time of their first ever hospitalization for a COPD exacerbation over the follow-up period, with the time between successive exacerbations estimated using the median inter-exacerbation times as time to the next exacerbation or death, whichever occurs first. Note: Adapted from Long-term natural history of chronic obstructive pulmonary disease: severe exacerbations and mortality, Suissa S, Dell'Aniello S, Ernst P, Volume 67, pages 957-963, copyright 2012 with permission from BMJ Publishing Group Ltd.

the previous year. ${ }^{30}$ Assessment of health-related QoL varies considerably between studies, and some measures do not include all domains of health status (physiological functioning, symptoms, functional impairment, and QoL). ${ }^{32}$

\section{Cardiovascular sequelae}

Cardiovascular comorbidities are common in patients with COPD, and particularly in those patients with more severe airflow limitation. A review of studies of patients hospitalized for COPD exacerbations found that up to $55 \%$ of patients had a history of cardiovascular disease..$^{33}$ Exacerbations of COPD have a profound effect on patients' cardiovascular status, ${ }^{33-35}$ and the increase in cardiac events after the first exacerbation is irrespective of the patient's cardiac history. ${ }^{36}$ Markers of myocardial injury, including raised troponin, chest pain, and serial electrocardiogram changes, are commonly observed in patients admitted to hospital with exacerbations of COPD. ${ }^{33,34}$ Levels of N-terminal pro-brain natriuretic peptide and cardiac troponin $\mathrm{T}$ are elevated during acute exacerbations of COPD and thought to be a predictor of mortality among patients admitted to hospital. ${ }^{37}$ Arterial stiffness also rises acutely during COPD exacerbations, particularly when associated with airway infection. ${ }^{35}$ These changes may also be associated with an acute increase in the risk of myocardial infarction (MI): a UK observational database study found a 2.3 -fold increase in the risk of MI 1-5 days postexacerbation, ${ }^{38}$ while analysis from the UPLIFT ${ }^{\circledR}$ study showed 13 -fold increased risk of MI in the 30 days postexacerbation compared with preexacerbation periods. A 17-fold increase in the occurrence of atrial fibrillation/flutter was also seen in the 30-day postexacerbation period. ${ }^{36}$

Increased prevalence of pulmonary embolism has also been reported in patients with COPD exacerbations. Two meta-analyses have reported an overall incidence of pulmonary embolism of $16 \%{ }^{39}$ and $20 \%,{ }^{40}$ increasing to $25 \%$ in hospitalized patients, including those hospitalized specifically for a COPD exacerbation. ${ }^{40}$

\section{What is the epidemiology and economic impact of severe exacerbations?}

Rates of hospitalization for exacerbations of COPD vary in different countries, which may reflect differences in the organization of health-care systems. A large international survey of more than 4,000 patients with COPD sampled from 12 countries in Europe, the US, and Asia (Continuing to Confront COPD International Patient Survey) found that overall, $15 \%$ of patients had been hospitalized for an exacerbation in the previous 12 months, with rates ranging $5 \%-25 \%$ across individual countries (Figure 2). ${ }^{41}$ In another large multinational survey of more than 1,000 patients in Germany, France, Italy, Spain, the UK, and the US (PERCEIVE), $21 \%$ of patients who reported a COPD exacerbation in the preceding year were hospitalized..$^{42}$

Severe COPD exacerbations are estimated to account for less than $10 \%$ of exacerbations, ${ }^{43,44}$ but have a disproportionate and significant socioeconomic impact, with hospitalizations estimated to account for approximately $60 \%-70 \%$ of health-care costs associated with COPD, depending on the region. ${ }^{8,45}$ Illustrative of the costs associated with COPD exacerbations, a recent health-economics analysis conducted in the US, based on a data set from 2006, identified a total of 1,254,703 hospitalizations for COPD exacerbations, with total inpatient costs of $\$ 11.9$ billion over the year at a mean cost of $\$ 9,545$ per hospitalized exacerbation. ${ }^{46}$ The substantial burden of severe COPD exacerbations is apparent when considered in the context of overall health-care resource utilization. In the UK, acute exacerbations account for 115,000 hospital admissions per year, representing one of the most common reasons for emergency admission to hospital, ${ }^{47}$ while in Spain it is estimated that $1 \%-2 \%$ of all emergency-service visits and $10 \%$ of all medical admissions are attributable to COPD exacerbations. ${ }^{18}$

Despite trends toward an improvement in in-hospital mortality rates and a reduction in average length of hospital stay in the US, ${ }^{9,48}$ there has been no significant improvement in other indicators, including the number of hospital discharges, 


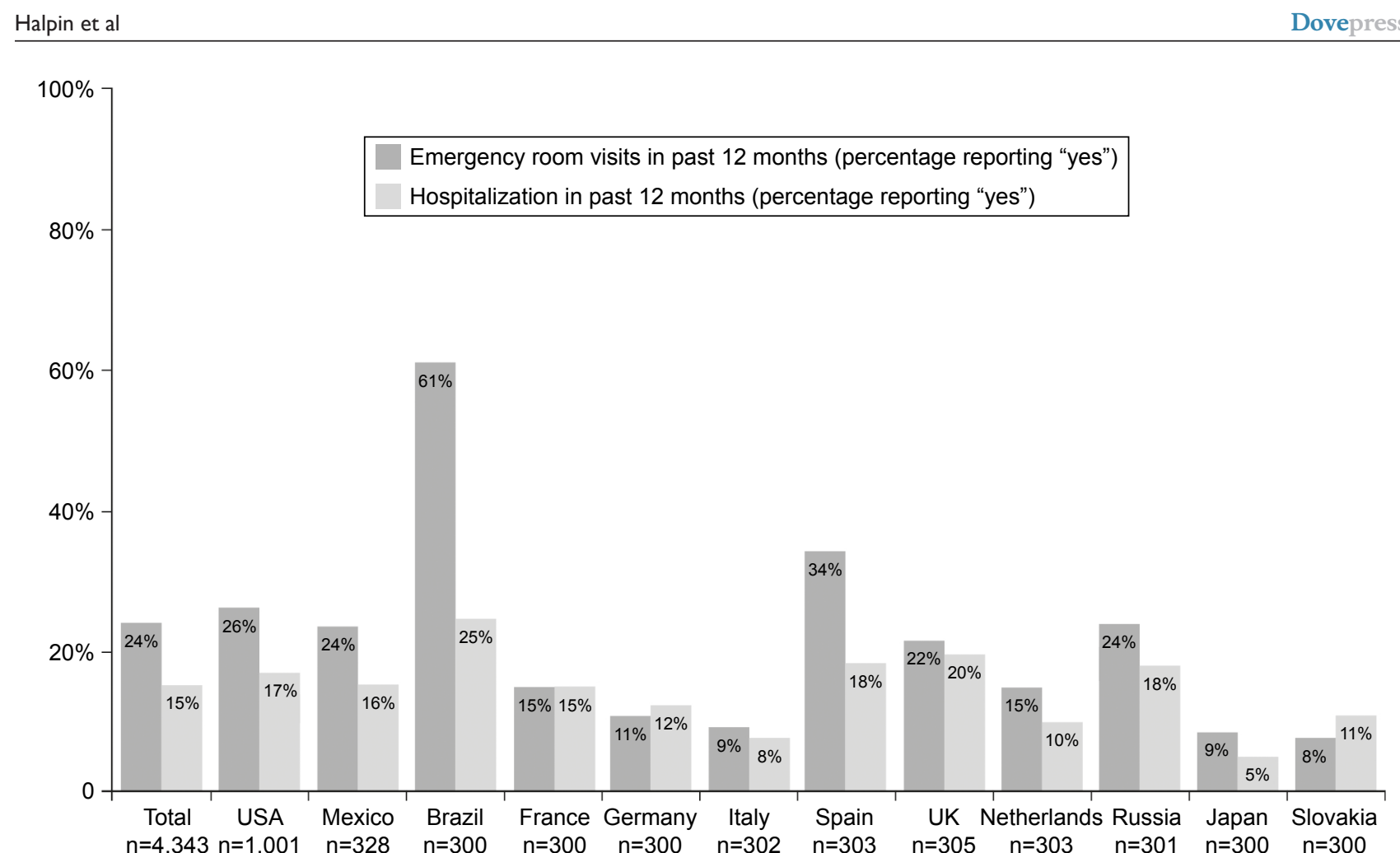

Figure 2 Emergency room visits and hospitalizations due to COPD exacerbations: Continuing to Confront COPD International Patient Survey.

Notes: Adapted with permission of Dove Medical Press Ltd, from Continuing to Confront COPD International Patient Survey: methods, COPD prevalence, and disease burden in 2012-2013, Landis SH, Muellerova H, Mannino DM, et al, Volume 9, Copyright 2006; permission conveyed through Copyright Clearance Center, Inc. ${ }^{41}$ Calculated from response to the questions "In the past 12 months, did any of these episodes (worsening of your breathing problems) require an ER visit?" and "In the past I 2 months, did any of these episodes (worsening of your breathing problems) require hospitalization?"

emergency-department visits, and 30-day readmissions within the period 2001-2012, ${ }^{48}$ highlighting considerable room for improvement and opportunities for reduction in the costs associated with admissions for COPD exacerbations. Patients who have been admitted to hospital for a severe exacerbation of COPD are at substantial risk for rehospitalization, ${ }^{19}$ with up to a quarter of patients readmitted for COPD exacerbations within 1 year following discharge. ${ }^{9,19}$ Strategies to reduce readmission rates are thus a priority in efforts to reduce the burden of severe COPD exacerbations.

\section{What are the risk factors associated with severe COPD exacerbations?}

The majority of COPD exacerbations, including severe exacerbations, are precipitated by respiratory tract infections, either viral or bacterial, or by environmental agents, eg, worsening air pollution. ${ }^{49}$ Numerous disease-related and demographic characteristics that modify patients' risk of having an exacerbation have been identified.

Severity of airflow limitation is a key risk factor for exacerbation requiring hospitalization. In a retrospective study of ambulatory COPD patients from general practices, severity of forced expiratory volume in 1 second impairment was a significant predictor for increased risk of hospitalizations, as was the presence of significant comorbidities, such as diabetes or ischemic heart disease. ${ }^{50}$ The cross-sectional analysis of the PAC-COPD study found that patients with more severe respiratory symptoms, poorer QoL, worse lung function, and lower exercise capacity were at greater than threefold-higher risk of hospitalization for COPD than those with milder airflow limitation, with or without significant comorbidities (hazard ratio 3.28, $P<0.001$ ). ${ }^{51}$

A summary of variables that have been shown to modify the risk of severe exacerbations of COPD is shown in Table 1. 4,6,18,19,26,50-78 These include lung function, symptoms (ie, severity of dyspnea), QoL, exacerbation history, disease history and treatment, age and sex, body-mass index, smoking status, and comorbidities. Other influences on the risk of severe COPD exacerbations include the patient's socioeconomic background, education level, and marital status.

Exacerbations may occur regardless of the degree of functional impairment, although it is generally agreed that the frequency of exacerbations increases with decreasing lung function. ${ }^{1}$ A major audit of COPD treatment and outcomes in Europe was conducted by the ERS between 2010 and 2011. This gathered a wealth of data (from more than 16,000 
Table I Risk factors for severe exacerbations in COPD

\begin{tabular}{|c|c|}
\hline \multicolumn{2}{|c|}{ Proposed risk factors for severe exacerbations by category } \\
\hline Lung function & - Lower lung-function levels lead to higher rates of severe exacerbations and hospitalizations. ${ }^{50-53,65,66,70,74}$ \\
\hline Dyspnea & $\begin{array}{l}\text { - Severe dyspnea and recurring exacerbations are related to high health-care resource utilization, including frequent } \\
\text { emergency visits and hospital admissions. } .^{6.54} \\
\text { - More than half (53\%) of patients with MRC breathlessness scale scores } 3-5 \text { in the Global Hidden Depths of COPD survey } \\
\text { had experienced an exacerbation requiring hospitalization in the previous year. } .^{57}\end{array}$ \\
\hline BODE index & $\begin{array}{l}\text { - Worsening (higher) BODE index score is associated with increased risk of exacerbation }{ }^{61} \text { and hospital admission for an } \\
\text { exacerbation. } .^{54,55}\end{array}$ \\
\hline Health status & $\begin{array}{l}\text { - Poor health status predicts increased hospitalizations. }{ }^{6,26,62,64,66} \\
\text { - Impairment in health status and quality of life in COPD is a marker of risk for both frequent exacerbations and hospital } \\
\text { admissions. }{ }^{77}\end{array}$ \\
\hline $\begin{array}{l}\text { Prior } \\
\text { exacerbations, } \\
\text { hospital visits, } \\
\text { and hospital } \\
\text { admissions }\end{array}$ & $\begin{array}{l}\text { - Frequency and proximity of previous exacerbations predicts subsequent exacerbations and hospitalizations. } .^{46,52,53,66,70,74,78} \\
\text { - History of hospitalized exacerbations in the past } 12 \text { months is the strongest risk factor for future hospitalized } \\
\text { exacerbation in ECLIPSE. }{ }^{6} \\
\text { - Severe exacerbation risk increases threefold after the second exacerbation requiring hospitalization and } 24 \text {-fold after the } \\
\text { tenth exacerbation. }{ }^{4} \\
\text { - Prior ER visits are a significant risk factor for exacerbation-related hospitalization. }{ }^{55}\end{array}$ \\
\hline Age & $\begin{array}{l}\text { - Older age is a significant risk factor for hospitalization. }{ }^{62,70} \\
\text { - Older age is associated with shorter time to first readmission. }{ }^{69}\end{array}$ \\
\hline $\begin{array}{l}\text { Duration of } \\
\text { COPD }\end{array}$ & $\begin{array}{l}\text { - Patients with a longer history of COPD ( }>5 \text { years) are approximately twice as likely to have frequent readmissions for } \\
\text { COPD exacerbations. }\end{array}$ \\
\hline Comorbidities & $\begin{array}{l}\text { - Presence of significant comorbidities (eg, diabetes mellitus, cardiac insufficiency, ischemic heart disease) is associated with } \\
\text { increase in risk, specifically for severe exacerbations requiring hospitalization. }{ }^{50} \\
\text { - Comorbidities associated with increased risk of hospitalization include cardiovascular disease, diabetes, asthma, psychiatric } \\
\text { disorders (anxiety, depression), gastroesophageal reflux disease, and pulmonary hypertension. }{ }^{19,50,58,64,68,75}\end{array}$ \\
\hline Blood-gas levels & $\begin{array}{l}\text { - Hypercapnia and poor arterial blood-oxygen saturation have been reported as being associated with hospitalization for a } \\
\text { COPD exacerbation. }{ }^{55,67}\end{array}$ \\
\hline BMI & - Low BMI is associated with hospitalization and readmission for COPD exacerbation. ${ }^{67,72}$ \\
\hline Smoking status & $\begin{array}{l}\text { - Evidence regarding impact of smoking status on risk of hospitalization is mixed, }{ }^{56} \text { with some studies suggesting current } \\
\text { smoking was associated with lower risk of hospitalization, }{ }^{52,70} \text { others finding no association, }{ }^{50,67} \text { and others indicating that } \\
\text { smoking cessation reduces risk. }{ }^{63}\end{array}$ \\
\hline Use of LTOT & $\begin{array}{l}\text { - Patients on LTOT are at increased risk of hospitalization for exacerbation. }{ }^{67} \\
\text { - Underprescription of LTOT increases the risk of hospitalization, due to severe exacerbations. }{ }^{52}\end{array}$ \\
\hline $\begin{array}{l}\text { Socioeconomic } \\
\text { status }\end{array}$ & $\begin{array}{l}\text { - Poorer health literacy increases the likelihood of COPD-related hospitalizations and emergency department visits. }{ }^{71} \\
\text { - Lowest education category and lowest income class are associated with a greater risk of hospitalization for } \\
\text { exacerbations. }{ }^{00} \\
\text { - Unmarried patients are at greater risk of hospital readmission than those with spousal support; patients requiring social } \\
\text { work intervention are likely to have an increased length of stay for hospitalized COPD exacerbations. }{ }^{76}\end{array}$ \\
\hline
\end{tabular}

Abbreviations: BMI, body-mass index; BODE, BMI, airway obstruction, dyspnea, and exercise capacity; ER, emergency room; LTOT, long-term oxygen therapy; MRC, Medical Research Council.

admissions) profiling the demographic and disease characteristics of patients admitted to hospital for exacerbations across the continent. ${ }^{10}$ The median age of patients admitted to hospital was 72 years. ${ }^{10}$ Many patients requiring hospitalization due to an exacerbation had severe (Global Initiative for Chronic Obstructive Lung Disease [GOLD] grade 3, 39\%) or very severe (GOLD grade 4, 22\%) underlying COPD, but the proportion of patients with mild or moderate disease who experienced a severe exacerbation was not insignificant (GOLD grade 1, 15\%; GOLD grade 2, 23\%). ${ }^{10}$ Major comorbidities included other pulmonary diseases $(21 \%)$, congestive heart failure $(20 \%)$, and diabetes $(20 \%) .^{10}$

A systematic review of 37 COPD-treatment studies, with mean forced expiratory volume in 1 second percentage predicted lung function of mostly $35 \%-60 \%$, estimated the annual frequency of severe exacerbations according to GOLD severity at 0.11 (GOLD grade $1,95 \%$ CI $0.02-0.56$ ), 0.16 (GOLD grade 2, 95\% CI 0.07-0.33), 0.22 (GOLD grade 3, 95\% CI $0.2-0.23$ ), and 0.28 (GOLD grade $4,95 \%$ CI 0.14-0.63) ${ }^{65}$ In the ECLIPSE study, exacerbations were more frequent and severe with increased severity of disease: the proportion of patients hospitalized for COPD exacerbations with GOLD grade 2-4 (moderate-very severe COPD) was $7 \%, 18 \%$, and $33 \%$, respectively. ${ }^{66}$

When we used the GOLD 2017 "ABCD" assessment tool (in which the lettering scale reflects symptom burden and risk of exacerbation ${ }^{11}$ to analyze patients included in the UPLIFT ${ }^{\circledR}$ trial, a greater proportion of patients 
(35\%) in GOLD group D with higher symptom burden or exacerbation risk had experienced a severe exacerbation compared with patients with lower symptom burden or exacerbation risk (GOLD group A, 14\%; group B, 22\%; group C, 21\%). Adjusted rates of severe COPD exacerbations (per patient-year) were (mean [95\% CI]): GOLD group A, 0.07 (0.05-0.09); group B, $0.13(0.12-0.14)$; group $\mathrm{C}$, 0.13 (0.09-0.19); group D $0.28(0.26-0.31)$ (Boehringer Ingelheim, data on file, 2017).

\section{What are the recommended treatment strategies for severe COPD exacerbations?}

Mortality statistics showing that the risk of death is highest in the first week following admission highlight the importance of prompt and effective intervention for patients admitted to hospital with severe exacerbations. ${ }^{4}$ Pharmacological treatment options for severe exacerbations include bronchodilators (short-acting $\beta$-agonists with or without short-acting anticholinergics), corticosteroids (CSs) (eg, prednisone), and antibiotics when the symptoms are suggestive of bacterial infection (eg, change in sputum characteristics). ${ }^{11,12}$ Full recommendations for the pharmacological treatment of exacerbations using bronchodilators can be found in published guidelines. ${ }^{11,12}$

\section{Antibiotics}

Based on available evidence that shows a reduced risk of short-term mortality and treatment failure, current GOLD recommendations are for antibiotic treatment in those patients whose exacerbation symptoms indicate likely bacterial infection, ie, increased sputum volume and purulence, as well as increased dyspnea. ${ }^{11}$ Antibiotics are also recommended for patients with exacerbations requiring mechanical ventilation, as this has been shown significantly to reduce mortality and the risk of secondary pneumonia. ${ }^{11}$

In this era of increasing antibiotic resistance, two key considerations are avoiding the use of unnecessary antibiotic treatment (ie, in patients who do not show an increase in purulent sputum $)^{13}$ and ensuring that empiric treatment choices are selected based on knowledge of local bacteria-resistance patterns. ${ }^{11}$ Treatment selection might also consider how the microbiology may differ in patients with severe exacerbations versus patients with mild or moderate disease. ${ }^{79}$ The most common pathogens isolated from sputum and bronchoscopic samples are Haemophilus influenzae, Streptococcus pneumoniae, and Moraxella catarrhalis. However, in patients with more severe disease and/or exacerbations, Gram-negative pathogens, such as Pseudomonas aeruginosa, are common, ${ }^{79,80}$ and may prove more challenging to treat in light of increasing resistance in some regions. The role of procalcitonin as a potential biomarker for optimizing antibiotic-treatment strategy in COPD exacerbations (especially those induced by bacterial infection) is also being investigated; however, as yet its role is unproven. ${ }^{81,82}$ Further studies are required to guide optimal antibiotic treatment, based on investigation of biomarkers to identify patients expected to benefit, and to establish the optimal duration of treatment. ${ }^{83}$

\section{Corticosteroids}

In the treatment of acute exacerbations of COPD, systemic CSs have been shown to reduce length of stay in hospital, provide earlier improvement in lung function and symptoms, and reduce the risk of treatment failure or relapse. ${ }^{84}$ However, a US study has noted that critically ill patients admitted directly to an intensive care unit for the treatment of severe exacerbations often receive higher-thanrecommended doses of CSs to combat inflammation in the lungs. ${ }^{85}$ A large cohort study of patients receiving low-dose (methylprednisolone $\leq 240 \mathrm{mg}$ /day; $\sim 6,000$ patients) or highdose (methylprednisolone $>240 \mathrm{mg} /$ day; $\sim 11,000$ patients) CS treatment found that outcomes were in fact worse for patients treated with high doses of CSs ${ }^{85}$ Higher doses were on average associated with longer hospital stays, longer time in the intensive care unit, and corresponding higher costs, as well as more steroid-related adverse events, compared with patients on lower doses of CSs. No significant difference was observed between patients treated with oral or intravenous CSs in terms of treatment failure, hospital readmissions, or length of hospitalization; however, intravenous therapy might increase the risk of adverse events. Overall, available evidence does not recommend one method of administration over the other. ${ }^{86}$

Optimal dosing regimens for oral CSs in patients with severe exacerbations have not been studied extensively; however, prolonged CS treatment is not recommended, in consideration of the adverse effects and lack of evidence for benefits of extended treatment. A recent meta-analysis suggested that a 5-day course of oral CSs was likely to be sufficient to treat patients hospitalized with a COPD exacerbation, and outcomes were not inferior to those with longer (10- to 14-day) courses. ${ }^{87}$

\section{Oxygen therapy}

During exacerbations, patients with COPD may become significantly hypoxic. ${ }^{88}$ Severe exacerbations disrupt the normal ventilation:perfusion ratio in the lungs, resulting in systemic hypoxemia, with poorly oxygenated blood returned to the left atrium. ${ }^{88}$ In a Spanish cohort of 2,487 patients 
attending the emergency department due to acute exacerbation of COPD, 50\% had hypoxemia (arterial oxygen saturation $\left.\left[\mathrm{SaO}_{2}\right]<90 \%\right) .{ }^{89}$ Oxygen therapy is a key component in hospital treatment of patients with a severe exacerbation. ${ }^{11}$

There are marked variations in the response of individual patients to oxygen, and oxygen therapy may lead to hypercapnia and acidosis..$^{90}$ Titrated controlled oxygen treatment for acute exacerbations has been associated with less acidosis, a lower requirement for assisted ventilation, and reduced mortality compared with high-flow oxygen. ${ }^{91,92}$ GOLD recommends titrating supplemental oxygen therapy to achieve a target saturation of $88 \%-92 \% .{ }^{11}$ To achieve optimal oxygenation without carbon dioxide retention and/or worsening acidosis, blood gases should be monitored frequently. ${ }^{11}$

\section{Ventilatory support}

Several studies have characterized the physiological changes that occur during or immediately after acute exacerbations, and have shown that lung hyperinflation and worsening airflow obstruction are the critical factors that determine the course of respiratory symptoms. ${ }^{93-95}$ Ventilatory support for the management of respiratory failure can be provided by either noninvasive or invasive methods, dependent upon patient criteria. Since its introduction in the 1980s, the use of noninvasive ventilation (NIV) has significantly increased, and has been associated with a reduction in mortality of approximately $40 \%$ and significantly reduced risk of treatment failure, complications, and endotracheal intubation. ${ }^{96}$ NIV is indicated in patients with respiratory acidosis (arterial $\mathrm{pH} \leq 7.35$ ), severe dyspnea with clinical indicators of respiratory muscle fatigue, increased work of breathing, or both, and in patients on supplemental oxygen therapy who continue to experience persistent hypoxemia. ${ }^{11}$

It has been observed that patients who fail NIV and then transition to invasive mechanical ventilation have a higher rate of mortality compared with patients who start directly with invasive ventilation. ${ }^{97}$ Therefore, it is important to evaluate further the factors that predict early failure of NIV: to date, studies have identified severe acidosis, tachycardia, high APACHE II score, and severe hypoxemia as risk factors for NIV failure in patients with COPD exacerbations. ${ }^{12,97-99}$ Further guidance on the use of ventilator support can be found in the GOLD report and ATS/ERS guidelines. ${ }^{11,12}$

\section{Preventing severe COPD exacerbations}

The profound impact of severe COPD exacerbations on patients' well-being and the substantial economic burden associated with hospitalization highlights the importance of risk reduction as a key component of COPD management. Strategies to reduce the risk of subsequent exacerbations following hospitalization might be considered secondary prevention in a similar way to the approach used in cardiology, using the index event as a critical point to review treatment and ensure optimal patient management to minimize the risk of future exacerbations.

\section{Risk-factor modification Smoking cessation}

Smoking cessation has a substantial influence on the natural history of COPD, and is associated with a decrease in symptoms and improved health status. In a large observational cohort study of 23,971 US veterans, ex-smokers had a significantly reduced risk of COPD exacerbation compared with current smokers. ${ }^{100}$ The magnitude of reduction in risk was dependent on the duration of smoking cessation. Despite the evidence supporting the significant risk reductions that can be achieved through smoking cessation, a substantial proportion of patients continue to smoke. For example, the EU COPD audit data showed that approximately a third of patients admitted to hospital with severe exacerbations in Europe in 2010-2011 were current smokers. ${ }^{10}$ Reinforcing participation in smoking-cessation programs represents a significant opportunity to reduce exacerbation risk by targeting a modifiable risk factor, particularly at hospital discharge, when patients may be particularly motivated to stop smoking to avoid experiencing another severe exacerbation.

\section{Vaccinations}

Vaccination against influenza is a highly cost-effective intervention for exacerbation reduction, ${ }^{101}$ and is recommended for all patients. ${ }^{11}$ In a retrospective cohort study of 1,323 patients with COPD, vaccination against seasonal influenza significantly reduced hospitalization due to exacerbation versus patients who were not vaccinated. ${ }^{102}$ Protection may be enhanced by the addition of pneumococcal vaccine (although additive effects of influenza and pneumococcal vaccinations were only observed during the first year after vaccination). ${ }^{103}$

\section{Pulmonary rehabilitation}

Pulmonary rehabilitation may be offered after a severe exacerbation with the aim of restoring preexacerbation functional status, resuming physical activities in daily life, improving QoL, and reducing the risk of further exacerbations. ${ }^{11,101}$ The reported benefits of pulmonary rehabilitation on exacerbations of COPD have been mixed, but the balance of evidence supports its use. ${ }^{104,105}$ In a meta-analysis of nine trials in 
patients who had been hospitalized for an exacerbation, pulmonary rehabilitation significantly reduced future hospital admissions and mortality and improved QoL compared with usual community care. ${ }^{106}$ Pulmonary rehabilitation may reduce future exacerbations by targeting modifiable risk factors for readmission, such as physical inactivity, reduced exercise capacity, impaired physical function, central desensitization to dyspnea, anxiety, and depression. ${ }^{73,104}$ Although the benefits of pulmonary rehabilitation are increasingly recognized and it is recommended in treatment guidelines for the prevention of acute exacerbations, ${ }^{11,13,107}$ availability of pulmonary rehabilitation programs is often limited. For example, among hospitals surveyed in the EU COPD audit, only half offered a pulmonary rehabilitation program to patients discharged following a severe exacerbation ( $0 \%-90 \%$ across countries) $)^{10}$ Identifying barriers to availability and uptake of pulmonary rehabilitation would be a useful step toward improving prevention strategies.

\section{Self-management intervention programs}

Self-management intervention programs improve outcomes for many chronic diseases. A disease-management plan for COPD should include an action plan for exacerbation prevention, designed in partnership with the physician and the patient, and taking into account the patient's experience of an acute (severe) exacerbation. ${ }^{101}$ Evidence for benefits of self-management plans for the prevention of COPD exacerbations is mixed. In one study, a self-management program for patients with COPD (comprising education on the disease, coughing and breathing techniques, energy conservation during daily activities, relaxation exercises, symptom prevention and control, an acute-exacerbation plan of action, and lifestyle advice, including nutrition and exercise) led to a $40 \%$ reduction in hospital admissions for exacerbations compared with usual care over 12 months. ${ }^{108}$ Emergency visits were also reduced by $41 \%$ and unscheduled physician visits by 59\%. ${ }^{108}$ Extended follow-up for 2 years demonstrated sustained benefits. ${ }^{62}$ A similar benefit was observed using a simplified disease-management program (a single education session, action plan for self-management of exacerbations, monthly follow-up calls). ${ }^{109}$ However, another randomized trial of patients with COPD found that a home education and management program did not result in a reduction in admissions for exacerbations, and in fact showed an unexpected increase in mortality. ${ }^{110}$ A Cochrane review suggested that overall, the balance of evidence supports the use of self-management programs to reduce the probability of respiratory-related hospitalizations, ${ }^{111}$ and the American College of Chest Physicians and Canadian Thoracic Society ${ }^{107}$ and ATS/ERS guidelines ${ }^{12}$ advocate their use.

\section{Pharmacological strategies Bronchodilators}

Pharmacological agents currently available as maintenance treatment for COPD have varying efficacy for the prevention of COPD exacerbations. Long-term bronchodilator treatment with a long-acting muscarinic antagonist (LAMA), long-acting $\beta_{2}$-agonist (LABA), or a combination of both have been shown to reduce the risk of severe exacerbations significantly. ${ }^{25,112,113}$ Table 2 provides a summary of largescale randomized trials comparing the efficacy of inhaled maintenance COPD therapies in reducing exacerbation risk. ${ }^{14-134}$ The evidence base for LAMAs appears to be strongest, with a recent systematic review demonstrating that tiotropium is beneficial in reducing exacerbation risk versus placebo or other maintenance treatments, with longer time to first exacerbation event and fewer exacerbations (including hospitalizations) than either placebo or most active-comparator treatments. ${ }^{113}$ A fixed-dose LAMA-LABA combination of glycopyrronium and indacaterol successfully reduced moderate-severe exacerbations in patients of GOLD grade 3 or 4 compared with glycopyrronium alone, but this was not significant for severe exacerbations only. ${ }^{130}$ The FLAME study found that the combination of indacaterolglycopyrronium significantly prolonged time to first severe exacerbation compared with salmeterol-fluticasone, although the annual rate of severe exacerbations was not significantly different between the two treatment groups; however, it has to be noted that the FLAME study was not powered to analyze differences in severe exacerbations between groups. ${ }^{133}$

Despite the wealth of evidence to support tiotropium and other LAMAs in reducing the risk of severe exacerbations, data from the EU COPD audit indicate that they may be underutilized. Fewer than half of patients were on LAMA treatment prior to hospitalization, even though this patient population had been hospitalized once on average in the past year. ${ }^{10}$ Discharge following an exacerbation presents a pivotal opportunity to ensure that maintenance treatment is optimized, in line with goal-directed treatment guidelines to reduce the risk of disease progression, exacerbations, and mortality. Medication review at discharge, and at the same time also ensuring correct inhaler technique, represents a valuable opportunity for improvements in pharmacological approaches to reducing exacerbation risk. Adhering to COPD-treatment guideline recommendations is likely to 


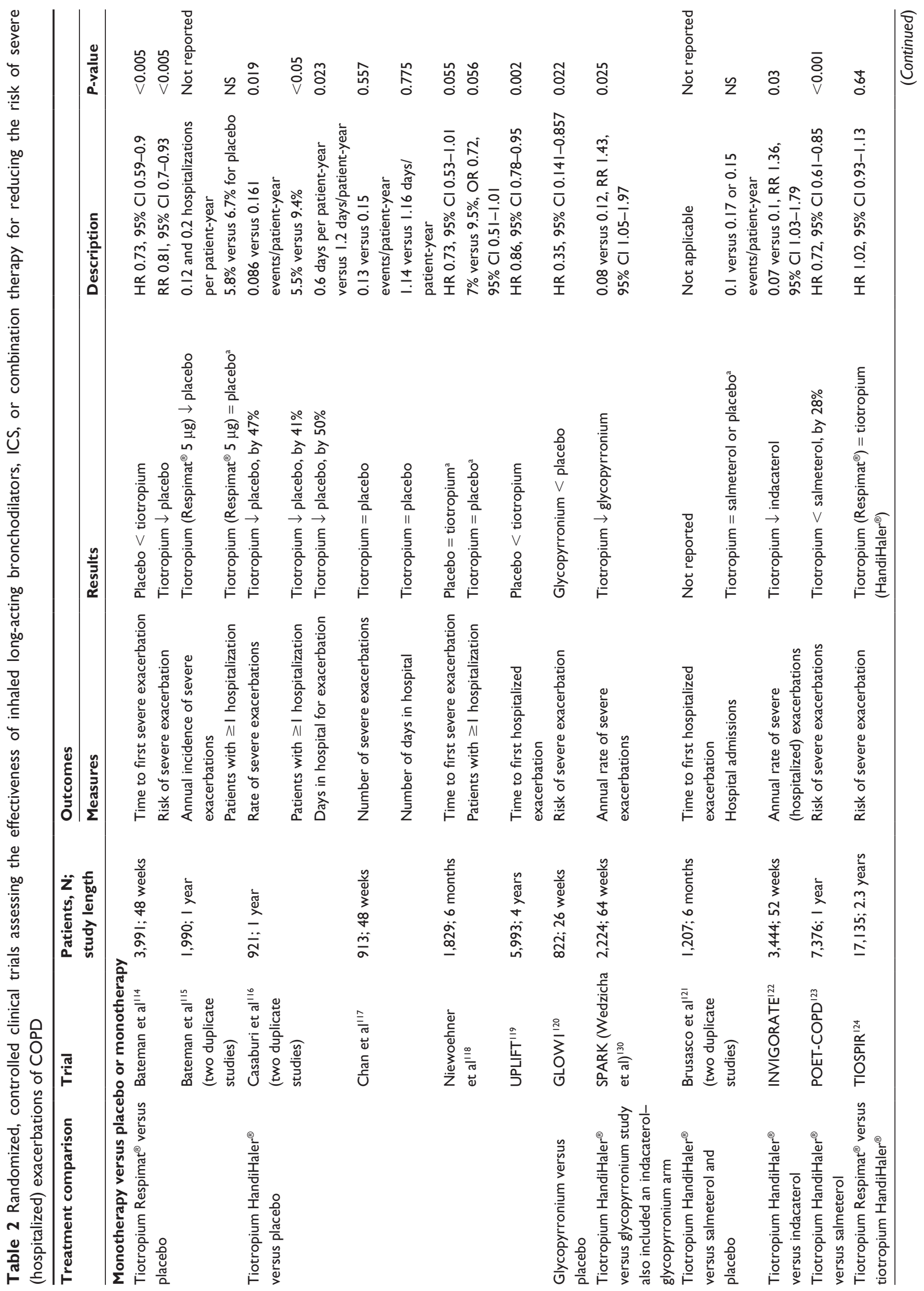




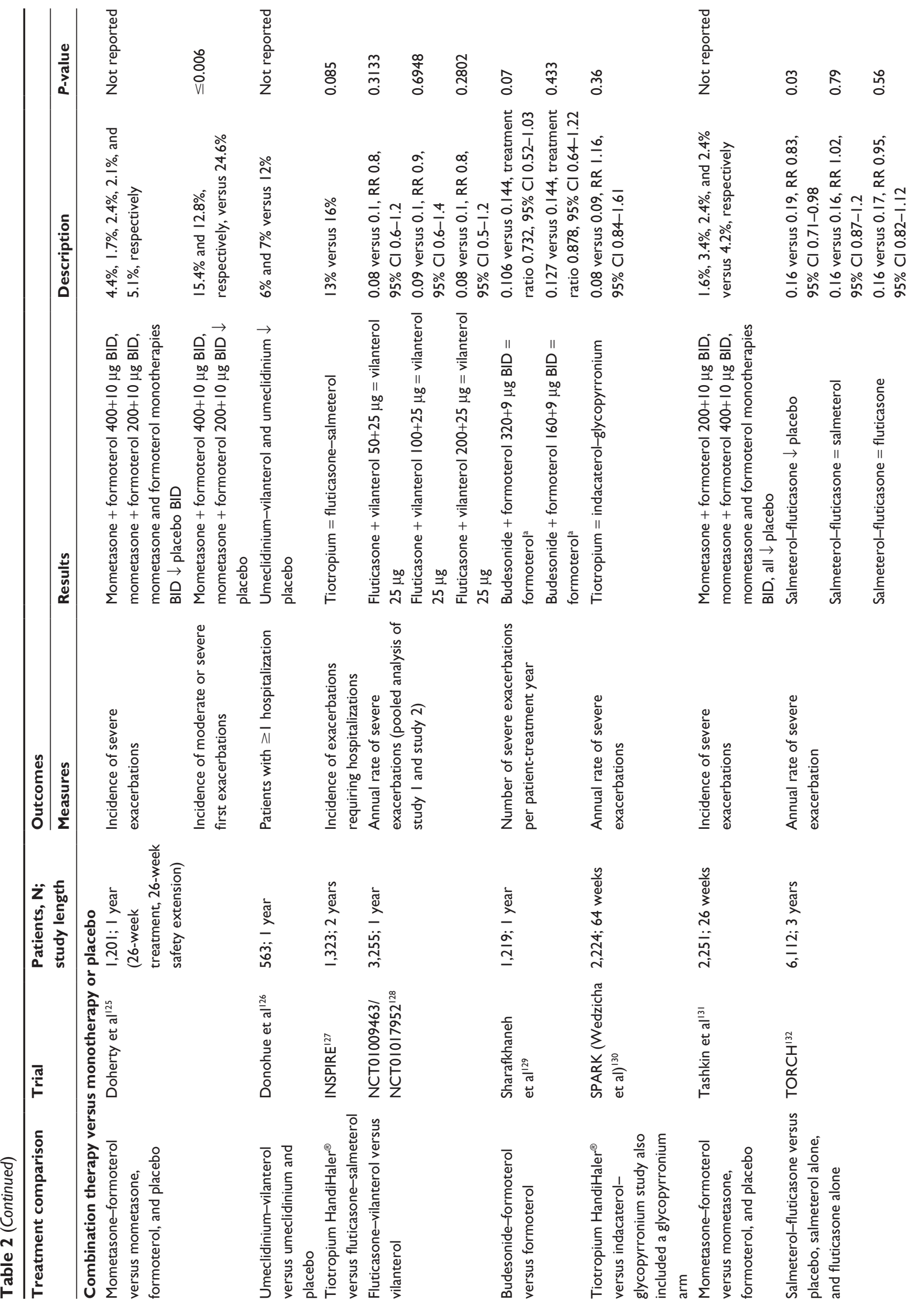


have a positive impact in terms of reducing the incidence of severe exacerbations. GOLD-adherent prescribing in COPD has been associated with significant reductions in proportions of patients with all-cause hospitalizations and emergency-department visits compared with nonadherent prescribing. ${ }^{135}$

\section{ICS and ICS combinations}

Due to the possible adverse events of pneumonia and fractures resulting from inhaled CS (ICS) treatment, current guidelines recommend ICS-combination therapy only in patients with severe airflow limitation at minimum and/or with frequent exacerbations that are not controlled adequately with longacting bronchodilators alone. ${ }^{11,13}$ The 3-year TORCH study found the ICS-LABA fluticasone-salmeterol combination therapy more effective than salmeterol alone in preventing moderate and severe exacerbations combined (rate ratio 0.88 ), but not for severe exacerbations only. ${ }^{132}$ The overall lack of significant benefits of ICS-LABA treatment over LABA monotherapy was demonstrated in a systematic review of 18 randomized controlled trials, which failed to show a significant decrease in the number of severe exacerbations. ${ }^{136}$

\section{Phosphodiesterase-4 inhibitors}

Phosphodiesterase-4 inhibitors do not have direct bronchodilator activity, but act as anti-inflammatory agents by inhibiting the breakdown of intracellular cyclic nucleotides. ${ }^{137}$ Roflumilast is an oral phosphodiesterase-4 inhibitor, indicated as a maintenance treatment for severe COPD associated with chronic bronchitis in adult patients with a history of frequent exacerbations (as add-on to bronchodilator treatment). ${ }^{138}$ The 1-year REACT study showed that in symptomatic patients with severe COPD and a history of exacerbations, roflumilast significantly reduced the risk of severe exacerbations in those already receiving an ICSLABA fixed combination, along with a LAMA (tiotropium in this study) as background treatment. ${ }^{139} \mathrm{~A}$ pooled analysis of two randomized trials enrolling patients with similar disease characteristics (but where approximately $50 \%$ continued with LABA therapy, and ICSs were not permitted) demonstrated that roflumilast reduced the rate of moderate-severe exacerbations versus placebo, but had no significant impact on the rate of severe exacerbations. ${ }^{140} \mathrm{~A}$ post hoc analysis of the 52-week RE ${ }^{2}$ SPOND trial showed that roflumilast reduced the rate of severe exacerbations in patients with frequent exacerbations (more than three exacerbations in the previous year) and/or history of hospitalization. ${ }^{141}$ The $\mathrm{RE}^{2} \mathrm{SPOND}^{141}$ and REACT ${ }^{139}$ studies were performed in 
patients with severe COPD, and evidence from these trials suggests that the benefits of roflumilast are demonstrated most consistently in patients with severe-very severe COPD associated with chronic bronchitis and a history of frequent exacerbations. ${ }^{142}$ Concerns have been raised regarding the safety profile of roflumilast, due to higher incidences of adverse events compared to other COPD medications; ${ }^{11}$ however, a benefit-harm analysis of the use of roflumilast found a net benefit in patients with a high risk of severe exacerbations. ${ }^{143}$

\section{Mucolytics}

Mucolytic agents (specifically $N$-acetylcysteine [NAC]) may have a beneficial role in exacerbation reduction, with studies indicative of a reduction in exacerbation frequency. ${ }^{144,145}$ Although a Cochrane systematic review concluded that the small reduction in overall acute exacerbations achieved with mucolytics may have been overestimated, ${ }^{146}$ some studies suggest that higher doses of mucolytics (NAC $600 \mathrm{mg}$ twice daily) may be particularly effective in patients with stable COPD, ${ }^{144}$ moderate-severe COPD,${ }^{147}$ or at high risk of exacerbations. ${ }^{148}$ However, these studies were not specifically powered for the analysis of severe exacerbations. The current GOLD report concludes that regular use of mucolytic agents, such as NAC and carbocysteine, reduce the risk of exacerbation when used in appropriate patients. ${ }^{11}$

\section{Antibiotic prophylaxis}

Several studies suggest that the use of certain types of antibiotics may have a role in preventing exacerbations in certain groups of patients for whom the benefits outweigh the risks. Macrolides, which possess both antibacterial and anti-inflammatory effects, and fluoroquinolones are the classes of antibiotics studied most extensively for use in stable COPD, and prophylactic use over 1 year can reduce the rate of hospitalizations for COPD exacerbations compared with placebo. ${ }^{149-153}$ While a meta-analysis of nine studies showed that macrolides are effective in reducing the overall rate of COPD exacerbations when administered for 6-12 months, the analysis was not able to demonstrate an effect on hospitalization rates, due to the low number of hospitalizations in the studies, which were not powered to detect such differences. ${ }^{151}$ Prophylactic antibiotic therapy should be applied cautiously, as the evidence remains limited, and further studies will be required to determine the optimal treatment regimen and duration with prophylactic use of antibiotics, and in what patients, to maintain a positive benefit-risk balance. ${ }^{150,151,154}$

\section{Vitamin D}

It has been suggested that vitamin D supplements may help to prevent COPD exacerbations. The ViDiCO study demonstrated that vitamin $\mathrm{D}_{3}$ supplementation reduced the risk of moderate and severe exacerbations in patients with COPD ${ }^{155}$ however, findings have been conflicting and the benefits may only be evident in patients with severe vitamin $\mathrm{D}$ deficiency. ${ }^{156}$ The PRECOVID study will be the first randomized trial to evaluate the effects of vitamin D supplementation on exacerbation prevention (primary outcome; rates of hospitalization will be a secondary outcome), and will recruit vitamin D-deficient patients who have recently experienced an exacerbation. ${ }^{157}$ The results of the study will be beneficial for establishing guidelines for vitamin D supplementation with regard to reducing exacerbation rates.

\section{$\beta$-Blockers}

$\beta$-blocker usage is low in patients with COPD and cardiovascular comorbidities, as blockade of $\beta$-adrenergic receptors might induce bronchoconstriction and lead to bronchospasm and worsening of lung function. This is based largely on anecdotal evidence; however, review of the evidence base has indicated that cardioselective $\beta$-blockers (ie, those with greater affinity for $\beta_{1}$ - over $\beta_{2}$-receptors) reduce overall mortality in patients with such conditions as coronary artery disease or MI and coexisting mild-moderate COPD, without producing clinically significant adverse respiratory effects, and should not be withheld. ${ }^{158-160}$ One observational cohort study (COPDGene ${ }^{\circledR}$ ), which followed approximately 3,500 patients for a median of 2.1 years, indicated that the use of $\beta$-blockers in COPD patients with cardiovascular comorbidities was associated with a significant reduction in exacerbation rates, including severe exacerbations. Effects were most pronounced in patients with severe COPD (GOLD grade 3 and 4 on home oxygen therapy). ${ }^{161}$ Randomized trials may be warranted to confirm whether this observation represents beneficial effects of $\beta$-blockers in COPD and explore the mechanisms underlying potential protective effects.

\section{Readmissions}

Patients who have been admitted to hospital for a severe exacerbation of COPD are at substantial risk of rehospitalization. ${ }^{18}$ In the EU COPD audit, $35 \%$ of all patients admitted to hospital with COPD exacerbations were readmitted within 90 days, and approximately three-quarters of readmissions were recorded as COPD-related. ${ }^{10}$ Readmission is a poor outcome for patients, and presents a significant strain on resources. In some cases, readmission is the result of a poor discharge, while in others it reflects the severity of the 
underlying COPD or the presence of comorbidities. ${ }^{162}$ Despite best efforts, many readmissions may not be preventable. The US National COPD Readmissions Summit, as well as a recent systematic review, found that the evidence base to support specific interventions that would significantly reduce 30-day readmission rates in patients hospitalized for COPD exacerbations was inadequate. ${ }^{163,164}$

Nevertheless, readmission rates are of increasing significance to payers in both the US and the UK, where financial penalties have been imposed on hospitals with higher-thanexpected readmission rates, as part of an incentive to promote optimized, value-driven care packages for patients discharged following a COPD exacerbation. From a clinical perspective, it is important to monitor whether these approaches have unintended negative consequences, such as an increase in out-of-hospital mortality resulting from the disincentive to readmit patients who might genuinely benefit from further hospital treatment. ${ }^{163}$

Since a substantial proportion of readmissions are not due to COPD itself, but relate to comorbidities, effective management of these conditions and COPD is important in attempts to reduce readmission rates. ${ }^{56,162}$ Ensuring patients are on optimal maintenance treatment known to reduce exacerbation rates (as discussed earlier) at the time of discharge is essential to reduce the risk of further exacerbations and readmission.

\section{Improving overall disease- management strategies}

Several studies have revealed the frequency of clinical practices that are nonadherent to treatment guidelines, showing a disparity in treatment choices, overuse of CSs and antibiotics, and underuse of pulmonary rehabilitation. ${ }^{162-167}$ In a study conducted in the US, review of medical records indicated that patients with COPD received only $58 \%$ of the care recommended by guidelines. ${ }^{168}$ A survey of respiratory specialists in Canada identified important care gaps regarding interventions to prevent future exacerbations, eg, suboptimal vaccinations, care plans, and patient education (39\% of patients had never been taught how to recognize the signs and symptoms of an exacerbation). In the Continuing to Confront COPD International Physician Survey (12 countries), only 57\% of primarycare physicians and $58 \%$ of respiratory specialists provided treatment options concordant with the GOLD report for high-risk (GOLD grade 4) COPD. ${ }^{165}$ The EU COPD audit showed that COPD treatment received before admission for COPD exacerbation, inpatient treatment, use of mechanical ventilation, and discharge medications (including oxygen) varied widely across Europe. ${ }^{10}$ In addition, the organization of COPD care and hospital facilities was shown to vary considerably between countries. ${ }^{10}$

Adherence to therapy is an important factor in successfully preventing exacerbations. Poor adherence to COPD medication detrimentally affects long-term disease outcomes. ${ }^{169}$ Among inhaled bronchodilators prescribed as maintenance therapy for COPD, adherence varies according to the type of medication, with higher rates of adherence observed with LAMAs (tiotropium in the study quoted) and relatively low adherence to ICSs or ICS-LABA combinations. ${ }^{170}$

\section{Conclusion}

Severe exacerbations are an important cause of morbidity and mortality, and have substantial economic consequences. A large number of potential risk factors are associated with severe exacerbations, many of which are easily identifiable and modifiable with careful patient management. Previous severe exacerbations and hospital readmission are significant risk factors for mortality; therefore, targeted interventions aimed at preventing or reducing severe exacerbations should be a priority for improving patients' prognoses. Strategies to reduce hospital readmissions for COPD and related comorbidities are also required to reduce the economic burden associated with repeated hospitalizations.

Recent observational studies have reported lower rates of in-hospital mortality, reduced length of hospitalization, and fewer subsequent exacerbations over the past decade, reflecting improvements in care and greater awareness of the impact of COPD exacerbations. Nonetheless, effective prevention of severe exacerbations remains a significant unmet need in COPD. Both pharmacological and nonpharmacological interventions have a role as part of a holistic package to minimize exacerbation risk. Smoking cessation is a key intervention, and improved access to/ uptake of pulmonary rehabilitation may be beneficial. Large randomized clinical trials have demonstrated the benefit of long-acting bronchodilators, such as LAMAs or LABAs, either as monotherapies or in combination, in reducing the risk of severe exacerbations in patients with COPD at all stages of severity. Overall, bronchodilators appear to be at least as effective as LABA-ICS therapy in preventing severe exacerbations of COPD. Antibiotics also have a role in selected patients, and influenza and pneumococcal vaccination can help prevent exacerbations. In conclusion, multiple opportunities to improve management of COPD and reduce risk of severe exacerbations are available, and should be considered in all patients with COPD, with particular attention paid to those who have already had a severe exacerbation. 


\section{Acknowledgments}

Editorial and writing support was provided by Andree Rose, Jennifer Fuchs, and Deepti Sharda at PAREXEL, funded by Boehringer Ingelheim.

\section{Disclosure}

DMGH has received personal fees from Almirall, Boehringer Ingelheim, GlaxoSmithKline, Intermune, Pfizer and Novartis, and non-financial support from Boehringer Ingelheim and Novartis. MM has received speaker fees from Almirall, Boehringer Ingelheim, Pfizer, AstraZeneca, Chiesi, Esteve, GlaxoSmithKline, Menarini, Novartis, Talecris-Grifols, Takeda-Nycomed, and Novartis, and consulting fees from Almirall, Boehringer Ingelheim, Pfizer, GlaxoSmithKline, Gebro Pharma, MediImmune, Novartis, Talecris-Grifols and Takeda-Nycomed. NM is an employee of Boehringer Ingelheim. BC has received fees for consulting from AstraZeneca, Boehringer Ingelheim, GlaxoSmithKline, MedImmune and Novartis.

\section{References}

1. Donaldson GC, Wedzicha JA. COPD exacerbations - 1: epidemiology. Thorax. 2006;61(2):164-168.

2. Anzueto A, Leimer I, Kesten S. Impact of frequency of COPD exacerbations on pulmonary function, health status and clinical outcomes. Int J Chron Obstruct Pulmon Dis. 2009;4:245-251.

3. Effing TW, Kerstjens HA, Monninkhof EM, et al. Definitions of exacerbations: does it really matter in clinical trials on COPD? Chest. 2009;136(3):918-923.

4. Suissa S, Dell'Aniello S, Ernst P. Long-term natural history of chronic obstructive pulmonary disease: severe exacerbations and mortality. Thorax. 2012;67(11):957-963.

5. Esteban C, Quintana JM, Moraza J, et al. Impact of hospitalisations for exacerbations of COPD on health-related quality of life. Respir Med. 2009;103(8):1201-1208.

6. Mullerova H, Maselli DJ, Locantore N, et al. Hospitalized exacerbations of COPD: risk factors and outcomes in the ECLIPSE cohort. Chest. 2015;147(4):999-1007.

7. Toy EL, Gallagher KF, Stanley EL, Swensen AR, Duh MS. The economic impact of exacerbations of chronic obstructive pulmonary disease and exacerbation definition: a review. COPD. 2010;7(3): 214-228.

8. Miravitlles M, Murio C, Guerrero T, Gisbert R. Pharmacoeconomic evaluation of acute exacerbations of chronic bronchitis and COPD. Chest. 2002;121(5):1449-1455.

9. Lima FV, Yen TY, Patel JK. Trends in in-hospital outcomes among adults hospitalized with exacerbation of chronic obstructive pulmonary disease. COPD. 2015;12(2):636-642.

10. European Respiratory Society. An International Comparison of COPD Care in Europe: Results of the First European COPD Audit. Lausanne, Switzerland: ERS; 2012.

11. Global Initiative for Chronic Obstructive Lung Disease. Global Strategy for the Diagnosis, Management, and Prevention of Chronic Obstructive Pulmonary Disease. Bethesda (MD): GOLD; 2017.

12. Celli BR, Macnee W. Standards for the diagnosis and treatment of patients with COPD: a summary of the ATS/ERS position paper. Eur Respir J. 2004;23(6):932-946.

13. National Institute for Health and Care Excellence. Chronic Obstructive Pulmonary Disease in Over 16s: Diagnosis and Management. London: NICE; 2010.
14. Zhong N, Moon HS, Lee KH, et al. Tiotropium safety and performance in Respimat (TIOSPIR): analysis of Asian cohort of COPD patients. Respirology. 2016;21(8):1397-1403.

15. Chenna PR, Mannino DM. Outcomes of severe COPD exacerbations requiring hospitalization. Semin Respir Crit Care Med. 2010;31(3): 286-294.

16. Halpin DM, Decramer M, Celli B, Kesten S, Liu D, Tashkin DP. Exacerbation frequency and course of COPD. Int J Chron Obstruct Pulmon Dis. 2012;7:653-661.

17. Cote CG, Dordelly LJ, Celli BR. Impact of COPD exacerbations on patient-centered outcomes. Chest. 2007;131(3):696-704.

18. Soler-Cataluna JJ, Martinez-Garcia MA, Roman SP, Salcedo E, Navarro M, Ochando R. Severe acute exacerbations and mortality in patients with chronic obstructive pulmonary disease. Thorax. 2005;60(11):925-931.

19. McGhan R, Radcliff T, Fish R, Sutherland ER, Welsh C, Make B. Predictors of rehospitalization and death after a severe exacerbation of COPD. Chest. 2007;132(6):1748-1755.

20. Groenewegen KH, Schols AM, Wouters EF. Mortality and mortalityrelated factors after hospitalization for acute exacerbation of COPD. Chest. 2003;124(2):459-467.

21. Gunen H, Hacievliyagil SS, Kosar F, et al. Factors affecting survival of hospitalised patients with COPD. Eur Respir J. 2005;26(2): 234-241.

22. Piquet J, Chavaillon JM, David P, Martin F, Blanchon F, Roche N. High-risk patients following hospitalisation for an acute exacerbation of COPD. Eur Respir J. 2013;42(4):946-955.

23. Almagro P, Salvado M, Garcia-Vidal C, et al. Recent improvement in long-term survival after a COPD hospitalisation. Thorax. 2010;65(4): 298-302.

24. Halpin D. Mortality in COPD: inevitable or preventable? Insights from the cardiovascular arena. COPD. 2008;5(3):187-200.

25. Pavord ID, Jones PW, Burgel PR, Rabe KF. Exacerbations of COPD. Int J Chron Obstruct Pulmon Dis. 2016;11 Spec Iss:21-30.

26. Fan VS, Curtis JR, Tu SP, McDonell MB, Fihn SD. Using quality of life to predict hospitalization and mortality in patients with obstructive lung diseases. Chest. 2002;122(2):429-436.

27. Molinari N, Briand C, Vachier I, et al. Hospitalizations for COPD exacerbations: trends and determinants of death. COPD. 2015;12(6): 621-627.

28. Steer J, Gibson GJ, Bourke SC. Predicting outcomes following hospitalization for acute exacerbations of COPD. QJM. 2010;103(11): 817-829.

29. Miravitlles M, Ferrer M, Pont A, et al. Effect of exacerbations on quality of life in patients with chronic obstructive pulmonary disease: a 2 year follow up study. Thorax. 2004;59(5):387-395.

30. Solem CT, Sun SX, Sudharshan L, Macahilig C, Katyal M, Gao X. Exacerbation-related impairment of quality of life and work productivity in severe and very severe chronic obstructive pulmonary disease. Int J Chron Obstruct Pulmon Dis. 2013;8:641-652.

31. Niewoehner DE. The impact of severe exacerbations on quality of life and the clinical course of chronic obstructive pulmonary disease. Am J Med. 2006;119(10 Suppl 1):38-45.

32. Verhage T, Boer L, Molema J, Heijdra Y, Dekhuijzen R, Vercoulen JH. Decline of health status sub-domains by exacerbations of chronic obstructive pulmonary disease: a prospective survey. Respiration. 2013; 85(3):236-243.

33. MacDonald MI, Shafuddin E, King PT, Chang CL, Bardin PG, Hancox RJ. Cardiac dysfunction during exacerbations of chronic obstructive pulmonary disease. Lancet Respir Med. 2016;4(2):138-148.

34. McAllister DA, Maclay JD, Mills NL, et al. Diagnosis of myocardial infarction following hospitalisation for exacerbation of COPD. Eur Respir J. 2012;39(5):1097-1103.

35. Patel AR, Kowlessar BS, Donaldson GC, et al. Cardiovascular risk, myocardial injury, and exacerbations of chronic obstructive pulmonary disease. Am J Respir Crit Care Med. 2013;188(9):1091-1099.

36. Halpin DM, Decramer M, Celli B, Kesten S, Leimer I, Tashkin DP. Risk of nonlower respiratory serious adverse events following COPD exacerbations in the 4-year UPLIFT trial. Lung. 2011;189(4):261-268. 
37. Chang CL, Robinson SC, Mills GD, et al. Biochemical markers of cardiac dysfunction predict mortality in acute exacerbations of COPD. Thorax. 2011;66(9):764-768.

38. Donaldson GC, Hurst JR, Smith CJ, Hubbard RB, Wedzicha JA. Increased risk of myocardial infarction and stroke following exacerbation of COPD. Chest. 2010;137(5):1091-1097.

39. Wang F, Cheng ZZ, Wang JL, Han WZ, Sun NN. [Incidence of pulmonary embolism in patients with acute exacerbations of chronic obstructive pulmonary disease: a meta-analysis]. Zhonghua Yi Xue Za Zhi. 2013;93(24):1868-1871. Chinese.

40. Rizkallah J, Man SF, Sin DD. Prevalence of pulmonary embolism in acute exacerbations of COPD: a systematic review and metaanalysis. Chest. 2009;135(3):786-793.

41. Landis SH, Muellerova H, Mannino DM, et al. Continuing to Confront COPD International Patient Survey: methods, COPD prevalence, and disease burden in 2012-2013. Int J Chron Obstruct Pulmon Dis. 2014; 9:597-611.

42. Miravitlles M, Anzueto A, Legnani D, Forstmeier L, Fargel M. Patient's perception of exacerbations of COPD: the PERCEIVE study. Respir Med. 2007;101(3):453-460.

43. Donaldson GC, Seemungal TA, Patel IS, Lloyd-Owen SJ, Wilkinson TM, Wedzicha JA. Longitudinal changes in the nature, severity and frequency of COPD exacerbations. Eur Respir J. 2003;22(6):931-936.

44. Cazzola M, Macnee W, Martinez FJ, et al. Outcomes for COPD pharmacological trials: from lung function to biomarkers. Eur Respir J. 2008;31(2):416-469.

45. Sullivan SD, Strassels SA, Smith DH. Characterization of the costs of chronic obstructive pulmonary disease (COPD) in the US. Eur Respir J. 2016;9 Suppl 23:412S.

46. Perera PN, Armstrong EP, Sherrill DL, Skrepnek GH. Acute exacerbations of COPD in the United States: inpatient burden and predictors of costs and mortality. COPD. 2012;9(2):131-141.

47. National Health Service England. Overview of potential to reduce lives lost from chronic obstructive pulmonary disease (COPD). 2014. Available from: https://www.england.nhs.uk/wp-content/uploads/2014/02/ rm-fs-6.pdf. Accessed March 11, 2016.

48. Ford ES. Hospital discharges, readmissions, and ED visits for COPD or bronchiectasis among US adults: findings from the nationwide inpatient sample 2001-2012 and Nationwide Emergency Department Sample 2006-2011. Chest. 2015;147(4):989-998.

49. Celli BR, Barnes PJ. Exacerbations of chronic obstructive pulmonary disease. Eur Respir J. 2007;29(6):1224-1238.

50. Miravitlles M, Guerrero T, Mayordomo C, Sanchez-Agudo L, Nicolau F, Segu JL. Factors associated with increased risk of exacerbation and hospital admission in a cohort of ambulatory COPD patients: a multiple logistic regression analysis. Respiration. 2000;67(5): 495-501

51. Garcia-Aymerich J, Gomez FP, Benet M, et al. Identification and prospective validation of clinically relevant chronic obstructive pulmonary disease (COPD) subtypes. Thorax. 2011;66(5):430-437.

52. Garcia-Aymerich J, Monso E, Marrades RM, et al. Risk factors for hospitalization for a chronic obstructive pulmonary disease exacerbation: EFRAM study. Am J Respir Crit Care Med. 2001;164(6):1002-1007.

53. Garcia-Aymerich J, Farrero E, Felez MA, Izquierdo J, Marrades RM, Anto JM. Risk factors of readmission to hospital for a COPD exacerbation: a prospective study. Thorax. 2003;58(2):100-105.

54. Garcia-Polo C, Alcazar-Navarrete B, Ruiz-Iturriaga LA, et al. Factors associated with high healthcare resource utilisation among COPD patients. Respir Med. 2012;106(12):1734-1742.

55. Alcazar B, Garcia-Polo C, Herrejon A, et al. Factors associated with hospital admission for exacerbation of chronic obstructive pulmonary disease. Arch Bronconeumol. 2012;48(3):70-76.

56. Bahadori K, FitzGerald JM. Risk factors of hospitalization and readmission of patients with COPD exacerbation: systematic review. Int J Chron Obstruct Pulmon Dis. 2007;2(3):241-251.

57. Barnes N, Calverley PM, Kaplan A, Rabe KF. Chronic obstructive pulmonary disease and exacerbations: patient insights from the global Hidden Depths of COPD survey. BMC Pulm Med. 2013;13:54.
58. Benson VS, Müllerová H, Vestbo J, Wedzicha JA, Patel A, Hurst JR Associations between gastro-oesophageal reflux, its management and exacerbations of chronic obstructive pulmonary disease. Respir Med. 2015;109(9):1147-1154.

59. Cao Z, Ong KC, Eng P, Tan WC, Ng TP. Frequent hospital readmissions for acute exacerbation of COPD and their associated factors. Respirology. 2006;11(2):188-195.

60. Eisner MD, Blanc PD, Omachi TA, et al. Socioeconomic status, race and COPD health outcomes. J Epidemiol Community Health. 2011; 65(1):26-34

61. Faganello MM, Tanni SE, Sanchez FF, Pelegrino NR, Lucheta PA, Godoy I. BODE index and GOLD staging as predictors of 1-year exacerbation risk in chronic obstructive pulmonary disease. Am J Med Sci. 2010;339(1):10-14

62. Gadoury MA, Schwartzman K, Rouleau M, et al. Self-management reduces both short- and long-term hospitalisation in COPD. Eur Respir J. $2005 ; 26(5): 853-857$.

63. Godtfredsen NS, Vestbo J, Osler M, Prescott E. Risk of hospital admission for COPD following smoking cessation and reduction: a Danish population study. Thorax. 2002;57(11):967-972.

64. Gudmundsson G, Gislason T, Janson C, et al. Risk factors for rehospitalisation in COPD: role of health status, anxiety and depression. Eur Respir J. 2005;26(3):414-419.

65. Hoogendoorn M, Feenstra TL, Hoogenveen RT, Al M, Mölken MR Association between lung function and exacerbation frequency in patients with COPD. Int J Chron Obstruct Pulmon Dis. 2010;5: 435-444.

66. Hurst JR, Vestbo J, Anzueto A, et al. Susceptibility to exacerbation in chronic obstructive pulmonary disease. $N$ Engl J Med. 2010;363(12): $1128-1138$

67. Kessler R, Faller M, Fourgaut G, Mennecier B, Weitzenblum E. Predictive factors of hospitalization for acute exacerbation in a series of 64 patients with chronic obstructive pulmonary disease. Am J Respir Crit Care Med. 1999;159(1):158-164.

68. Kim J, Lee JH, Kim Y, et al. Association between chronic obstructive pulmonary disease and gastroesophageal reflux disease: a national cross-sectional cohort study. BMC Pulm Med. 2013;13:51.

69. Lau AC, Yam LY, Poon E. Hospital re-admission in patients with acute exacerbation of chronic obstructive pulmonary disease. Respir Med. 2001;95(11):876-884

70. Niewoehner DE, Lokhnygina Y, Rice K, et al. Risk indexes for exacerbations and hospitalizations due to COPD. Chest. 2007;131(1):20-28.

71. Omachi TA, Sarkar U, Yelin EH, Blanc PD, Katz PP. Lower health literacy is associated with poorer health status and outcomes in chronic obstructive pulmonary disease. J Gen Intern Med. 2013; 28(1):74-81.

72. Pouw EM, Ten Velde GP, Croonen BH, Kester AD, Schols AM, Wouters EF. Early non-elective readmission for chronic obstructive pulmonary disease is associated with weight loss. Clin Nutr. 2000; 19(2):95-99.

73. Qureshi H, Sharafkhaneh A, Hanania NA. Chronic obstructive pulmonary disease exacerbations: latest evidence and clinical implications. Ther Adv Chronic Dis. 2014;5(5):212-227.

74. Roberts CM, Lowe D, Bucknall CE, Ryland I, Kelly Y, Pearson MG. Clinical audit indicators of outcome following admission to hospital with acute exacerbation of chronic obstructive pulmonary disease. Thorax. 2002;57(2):137-141.

75. Wedzicha JA, Brill SE, Allinson JP, Donaldson GC. Mechanisms and impact of the frequent exacerbator phenotype in chronic obstructive pulmonary disease. BMC Med. 2013;11:181.

76. Wong AW, Gan WQ, Burns J, Sin DD, van Eeden SF. Acute exacerbation of chronic obstructive pulmonary disease: influence of social factors in determining length of hospital stay and readmission rates. Can Respir J. 2008;15(7):361-364.

77. Miravitlles M, Calle M, Alvarez-Gutierrez F, Gobartt E, Lopez F, Martin A. Exacerbations, hospital admissions and impaired health status in chronic obstructive pulmonary disease. Qual Life Res. 2006;15(3): $471-480$. 
78. Miravitlles M, Garcia-Sidro P, Fernandez-Nistal A, et al. The chronic obstructive pulmonary disease assessment test improves the predictive value of previous exacerbations for poor outcomes in COPD. Int J Chron Obstruct Pulmon Dis. 2015;10:2571-2579.

79. Beasley V, Joshi PV, Singanayagam A, Molyneaux PL, Johnston SL, Mallia P. Lung microbiology and exacerbations in COPD. Int J Chron Obstruct Pulmon Dis. 2012;7:555-569.

80. Gallego M, Pomares X, Espasa M, et al. Pseudomonas aeruginosa isolates in severe chronic obstructive pulmonary disease: characterization and risk factors. BMC Pulm Med. 2014;14:103.

81. Corti C, Fally M, Fabricius-Bjerre A, et al. Point-of-care procalcitonin test to reduce antibiotic exposure in patients hospitalized with acute exacerbation of COPD. Int J Chron Obstruct Pulmon Dis. 2016;11:1381-1389.

82. Schuetz P, Müller B, Christ-Crain M, et al. Procalcitonin to initiate or discontinue antibiotics in acute respiratory tract infections. Cochrane Database Syst Rev. 2012;(9):CD007498.

83. Boersma WG. Antibiotics in acute exacerbations of COPD: the good, the bad and the ugly. Eur Respir J. 2012;40(1):1-3.

84. Walters JA, Tan DJ, White CJ, Gibson PG, Wood-Baker R, Walters EH. Systemic corticosteroids for acute exacerbations of chronic obstructive pulmonary disease. Cochrane Database Syst Rev. 2014;(9): CD001288.

85. Kiser TH, Allen RR, Valuck RJ, Moss M, Vandivier RW. Outcomes associated with corticosteroid dosage in critically ill patients with acute exacerbations of chronic obstructive pulmonary disease. Am J Respir Crit Care Med. 2014;189(9):1052-1064.

86. Wedzicha JA, Miravitlles M, Hurst JR, et al. Management of COPD exacerbations: a European Respiratory Society/American Thoracic Society guideline. Eur Respir J. 2017;49(3):1600791.

87. Walters JA, Tan DJ, White CJ, Wood-Baker R. Different durations of corticosteroid therapy for exacerbations of chronic obstructive pulmonary disease. Cochrane Database Syst Rev. 2014;(12): CD006897.

88. Brill SE, Wedzicha JA. Oxygen therapy in acute exacerbations of chronic obstructive pulmonary disease. Int J Chron Obstruct Pulmon Dis. 2014;9:1241-1252.

89. Quintana JM, Esteban C, Unzurrunzaga A, et al. Predictive score for mortality in patients with COPD exacerbations attending hospital emergency departments. BMC Med. 2014;12:66.

90. Plant PK, Owen JL, Elliott MW. One year period prevalence study of respiratory acidosis in acute exacerbations of COPD: implications for the provision of non-invasive ventilation and oxygen administration. Thorax. 2000;55(7):550-554.

91. Austin MA, Wills KE, Blizzard L, Walters EH, Wood-Baker R. Effect of high flow oxygen on mortality in chronic obstructive pulmonary disease patients in prehospital setting: randomised controlled trial. BMJ. 2010;341:c5462.

92. Wijesinghe M, Perrin K, Healy B, et al. Pre-hospital oxygen therapy in acute exacerbations of chronic obstructive pulmonary disease. Intern Med J. 2011;41(8):618-622.

93. Parker CM, Voduc N, Aaron SD, Webb KA, O’Donnell DE. Physiological changes during symptom recovery from moderate exacerbations of COPD. Eur Respir J. 2005;26(3):420-428.

94. Pinto-Plata VM, Livnat G, Girish M, et al. Systemic cytokines, clinical and physiological changes in patients hospitalized for exacerbation of COPD. Chest. 2007;131(1):37-43.

95. Stevenson NJ, Walker PP, Costello RW, Calverley PM. Lung mechanics and dyspnea during exacerbations of chronic obstructive pulmonary disease. Am J Respir Crit Care Med. 2005;172(12): 1510-1516.

96. Lightowler JV, Wedzicha JA, Elliott MW, Ram FS. Non-invasive positive pressure ventilation to treat respiratory failure resulting from exacerbations of chronic obstructive pulmonary disease: Cochrane systematic review and meta-analysis. BMJ. 2003;326(7382):185.

97. Ko BS, Ahn S, Lim KS, Kim WY, Lee YS, Lee JH. Early failure of noninvasive ventilation in chronic obstructive pulmonary disease with acute hypercapnic respiratory failure. Intern Emerg Med. 2015;10(7): 855-860.
98. Contou D, Fragnoli C, Cordoba-Izquierdo A, Boissier F, Brun-Buisson C, Thille AW. Noninvasive ventilation for acute hypercapnic respiratory failure: intubation rate in an experienced unit. Respir Care. 2013;58(12): 2045-2052.

99. Phua J, Kong K, Lee KH, Shen L, Lim TK. Noninvasive ventilation in hypercapnic acute respiratory failure due to chronic obstructive pulmonary disease vs. other conditions: effectiveness and predictors of failure. Intensive Care Med. 2005;31(4):533-539.

100. Au DH, Bryson CL, Chien JW, et al. The effects of smoking cessation on the risk of chronic obstructive pulmonary disease exacerbations. J Gen Intern Med. 2009;24(4):457-463.

101. Decramer M, Nici L, Nardini S, et al. Targeting the COPD exacerbation. Respir Med. 2008;102 Suppl 1:S3-S15.

102. Montserrat-Capdevila J, Godoy P, Marsal JR, Cruz I, Solanes M. [Effectiveness of influenza vaccination in preventing hospital admission due to exacerbations of chronic obstructive pulmonary disease]. Enferm Infecc Microbiol Clin. 2014;32(2):70-75. Spanish.

103. Furumoto A, Ohkusa Y, Chen M, et al. Additive effect of pneumococcal vaccine and influenza vaccine on acute exacerbation in patients with chronic lung disease. Vaccine. 2008;26(33):4284-4289.

104. Maddocks M, Kon SS, Singh SJ, Man WD. Rehabilitation following hospitalization in patients with COPD: can it reduce readmissions? Respirology. 2015;20(3):395-404.

105. Puhan MA, Scharplatz M, Troosters T, Steurer J. Respiratory rehabilitation after acute exacerbation of COPD may reduce risk for readmission and mortality: a systematic review. Respir Res. 2005;6:54.

106. Puhan MA, Gimeno-Santos E, Scharplatz M, Troosters T, Walters EH, Steurer J. Pulmonary rehabilitation following exacerbations of chronic obstructive pulmonary disease. Cochrane Database Syst Rev. 2011; (10):CD005305.

107. Criner GJ, Bourbeau J, Diekemper RL, et al. Prevention of acute exacerbations of COPD: American College of Chest Physicians and Canadian Thoracic Society guideline. Chest. 2015;147(4): 894-942.

108. Bourbeau J, Julien M, Maltais F, et al. Reduction of hospital utilization in patients with chronic obstructive pulmonary disease: a diseasespecific self-management intervention. Arch Intern Med. 2003;163(5): 585-591.

109. Rice KL, Dewan N, Bloomfield HE, et al. Disease management program for chronic obstructive pulmonary disease: a randomized controlled trial. Am J Respir Crit Care Med. 2010;182(7): 890-896.

110. Fan VS, Gaziano JM, Lew R, et al. A comprehensive care management program to prevent chronic obstructive pulmonary disease hospitalizations: a randomized, controlled trial. Ann Intern Med. 2012;156(10): 673-683.

111. Zwerink M, Brusse-Keizer M, van der Valk PD, et al. Self management for patients with chronic obstructive pulmonary disease. Cochrane Database Syst Rev. 2014;(3):CD002990.

112. Aaron SD. Management and prevention of exacerbations of COPD. BMJ. 2014;349:g5237.

113. Halpin DM, Vogelmeier C, Pieper MP, Metzdorf N, Richard F, Anzueto A. Effect of tiotropium on COPD exacerbations: a systematic review. Respir Med. 2016;114:1-8.

114. Bateman ED, Tashkin D, Siafakas N, et al. A one-year trial of tiotropium Respimat plus usual therapy in COPD patients. Respir Med. 2010;104(10):1460-1472.

115. Bateman E, Singh D, Smith D, et al. Efficacy and safety of tiotropium Respimat SMI in COPD in two 1-year randomized studies. Int J Chron Obstruct Pulmon Dis. 2010;5:197-208.

116. Casaburi R, Mahler DA, Jones PW, et al. A long-term evaluation of once-daily inhaled tiotropium in chronic obstructive pulmonary disease. Eur Respir J. 2002;19(2):217-224.

117. Chan CK, Maltais F, Sigouin C, Haddon JM, Ford GT. A randomized controlled trial to assess the efficacy of tiotropium in Canadian patients with chronic obstructive pulmonary disease. Can Respir J. 2007; 14(8):465-472. 
118. Niewoehner DE, Rice K, Cote C, et al. Prevention of exacerbations of chronic obstructive pulmonary disease with tiotropium, a once-daily inhaled anticholinergic bronchodilator. Ann Intern Med. 2005;143(5): 317-326.

119. Tashkin DP, Celli B, Senn S, et al. A 4-Year trial of tiotropium in chronic obstructive pulmonary disease. N Engl J Med. 2008;359(15): 1543-1554

120. D'Urzo A, Ferguson GT, van Noord JA, et al. Efficacy and safety of once-daily NVA237 in patients with moderate-to-severe COPD: the GLOW1 trial. Respir Res. 2011;7(12):156.

121. Brusasco V, Hodder R, Miravitlles M, Korducki L, Towse L, Kesten S. Health outcomes following treatment for six months with once daily tiotropium compared with twice daily salmeterol in patients with COPD. Thorax. 2003;58(5):399-404.

122. Decramer M, Chapman KR, Dahl R, et al. Once-daily indacaterol versus tiotropium for patients with severe chronic obstructive pulmonary disease (INVIGORATE): a randomised, blinded, parallel-group study. Lancet Respir Med. 2013;1(7):524-533.

123. Vogelmeier C, Hederer B, Glaab T, et al. Tiotropium versus salmeterol for the prevention of exacerbations of COPD. $N$ Engl J Med. 2011; 364(12):1093-1103.

124. Wise RA, Anzueto A, Cotton D, et al. Tiotropium Respimat inhaler and the risk of death in COPD. $N$ Engl J Med. 2013;369(16): 1491-1501

125. Doherty DE, Tashkin DP, Kerwin E, et al. Effects of mometasone furoate/formoterol fumarate fixed-dose combination formulation on chronic obstructive pulmonary disease (COPD): results from a 52 -week phase III trial in subjects with moderate-to-very severe COPD. Int J Chron Obstruct Pulmon Dis. 2012;7:57-71.

126. Donohue JF, Niewoehner D, Brooks J, O’Dell D, Church A. Safety and tolerability of once-daily umeclidinium/vilanterol 125/25 mcg and umeclidinium $125 \mathrm{mcg}$ in patients with chronic obstructive pulmonary disease: results from a 52-week, randomized, double-blind, placebocontrolled study. Respir Res. 2014;15:78.

127. Wedzicha JA, Calverley PM, Seemungal TA, Hagan G, Ansari Z, Stockley RA. The prevention of chronic obstructive pulmonary disease exacerbations by salmeterol/fluticasone propionate or tiotropium bromide. Am J Respir Crit Care Med. 2008;177(1):19-26.

128. Dransfield MT, Bourbeau J, Jones PW, et al. Once-daily inhaled fluticasone furoate and vilanterol versus vilanterol only for prevention of exacerbations of COPD: two replicate double-blind, parallelgroup, randomised controlled trials. Lancet Respir Med. 2013;1(3): 210-223.

129. Sharafkhaneh A, Southard JG, Goldman M, Uryniak T, Martin UJ. Effect of budesonide/formoterol pMDI on COPD exacerbations: a double-blind, randomized study. Respir Med. 2012;106(2): 257-268.

130. Wedzicha JA, Decramer M, Ficker JH, et al. Analysis of chronic obstructive pulmonary disease exacerbations with the dual bronchodilator QVA149 compared with glycopyrronium and tiotropium (SPARK): a randomised, double-blind, parallel-group study. Lancet Respir Med. 2013;1(3):199-209.

131. Tashkin DP, Doherty DE, Kerwin E, et al. Efficacy and safety characteristics of mometasone furoate/formoterol fumarate fixed-dose combination in subjects with moderate to very severe COPD: findings from pooled analysis of two randomized, 52-week placebo-controlled trials. Int J Chron Obstruct Pulmon Dis. 2012;7:73-86.

132. Calverley PM, Anderson JA, Celli B, et al. Salmeterol and fluticasone propionate and survival in chronic obstructive pulmonary disease. N Engl J Med. 2007;356(8):775-789.

133. Wedzicha JA, Banerji D, Chapman KR, et al. Indacaterol-glycopyrronium versus salmeterol-fluticasone for COPD. $N$ Engl J Med. 2016;374(23):2222-2234.

134. Buhl R, Gessner C, Schuermann W, et al. Efficacy and safety of oncedaily QVA149 compared with the free combination of once-daily tiotropium plus twice-daily formoterol in patients with moderate-tosevere COPD (QUANTIFY): a randomised, non-inferiority study. Thorax. 2015;70(4):311-319.
135. Mannino DM, Yu TC, Zhou H, Higuchi K. Effects of GOLD-adherent prescribing on COPD symptom burden, exacerbations, and health care utilization in a real-world setting. Chronic Obstr Pulm Dis. 2015;2(3):223-235.

136. Rodrigo GJ, Castro-Rodriguez JA, Plaza V. Safety and efficacy of combined long-acting $\beta$-agonists and inhaled corticosteroids vs longacting $\beta$-agonists monotherapy for stable COPD: a systematic review. Chest. 2009;136(4):1029-1038.

137. Rabe KF. Update on roflumilast, a phosphodiesterase 4 inhibitor for the treatment of chronic obstructive pulmonary disease. Br J Pharmacol. 2011;163(1):53-67.

138. Roflumilast [summary of product characteristics]. Luton, UK: AstraZeneca UK

139. Martinez FJ, Calverley PM, Goehring UM, Brose M, Fabbrit LM, Rabe KF. Effect of roflumilast on exacerbations in patients with severe chronic obstructive pulmonary disease uncontrolled by combination therapy (REACT): a multicentre randomised controlled trial. Lancet 2015;385(9971):857-866.

140. Calverley PM, Rabe KF, Goehring UM, Kristiansen S, Fabbri LM, Martinez FJ. Roflumilast in symptomatic chronic obstructive pulmonary disease: two randomised clinical trials. Lancet. 2009;374(9691): 685-694.

141. Martinez FJ, Rabe KF, Sethi S, et al. Effect of roflumilast and inhaled corticosteroid/long-acting $\beta_{2}$-agonist on chronic obstructive pulmonary disease exacerbations ( $\mathrm{RE}^{2} \mathrm{SPOND}$ ): a randomized clinical trial. Am J Respir Crit Care Med. 2016;194(5):559-567.

142. Wedzicha JA, Calverley PM, Rabe KF. Roflumilast: a review of its use in the treatment of COPD. Int J Chron Obstruct Pulmon Dis. 2016; 11:81-90.

143. Yu T, Fain K, Boyd CM, et al. Benefits and harms of roflumilast in moderate to severe COPD. Thorax. 2014;69(7):616-622.

144. Tse HN, Raiteri L, Wong KY, et al. High-dose N-acetylcysteine in stable COPD: the 1-year, double-blind, randomized, placebocontrolled HIACE study. Chest. 2013;144(1):106-118.

145. Pela R, Calcagni AM, Subiaco S, Isidori P, Tubaldi A, Sanguinetti CM. $\mathrm{N}$-acetylcysteine reduces the exacerbation rate in patients with moderate to severe COPD. Respiration. 1999;66(6):495-500.

146. Poole P, Black PN, Cates CJ. Mucolytic agents for chronic bronchitis or chronic obstructive pulmonary disease. Cochrane Database Syst Rev. 2012;(8):CD001287.

147. Zheng JP, Wen FQ, Bai CX, et al. Twice daily N-acetylcysteine $600 \mathrm{mg}$ for exacerbations of chronic obstructive pulmonary disease (PANTHEON): a randomised, double-blind placebo-controlled trial. Lancet Respir Med. 2014;2(3):187-194.

148. Tse HN, Raiteri L, Wong KY, Ng LY, Yee KS, Tseng CZ. Benefits of high-dose $\mathrm{N}$-acetylcysteine to exacerbation-prone patients with COPD. Chest. 2014;146(3):611-623.

149. Albert RK, Connett J, Bailey WC, et al. Azithromycin for prevention of exacerbations of COPD. N Engl J Med. 2011;365(8):689-698.

150. Herath SC, Poole P. Prophylactic antibiotic therapy for chronic obstructive pulmonary disease (COPD). Cochrane Database Syst Rev. 2013;11:CD009764

151. Ni W, Shao X, Cai X, et al. Prophylactic use of macrolide antibiotics for the prevention of chronic obstructive pulmonary disease exacerbation: a meta-analysis. PLoS One. 2015;10(3):e0121257.

152. Pomares X, Monton C, Espasa M, Casabon J, Monso E, Gallego M. Longterm azithromycin therapy in patients with severe COPD and repeated exacerbations. Int J Chron Obstruct Pulmon Dis. 2011;6:449-456.

153. Seemungal TA, Wilkinson TM, Hurst JR, Perera WR, Sapsford RJ, Wedzicha JA. Long-term erythromycin therapy is associated with decreased chronic obstructive pulmonary disease exacerbations. Am J Respir Crit Care Med. 2008;178(11):1139-1147.

154. Miravitlles M, Anzueto A. Antibiotic prophylaxis in COPD: why, when, and for whom? Pulm Pharmacol Ther. 2015;32:119-123.

155. Martineau AR, James WY, Hooper RL, et al. Vitamin $D_{3}$ supplementation in patients with chronic obstructive pulmonary disease (ViDiCO): a multicentre, double-blind, randomised controlled trial. Lancet Respir Med. 2015;3(2):120-130. 
156. Lehouck A, Mathieu C, Carremans C, et al. High doses of vitamin D to reduce exacerbations in chronic obstructive pulmonary disease: a randomized trial. Ann Intern Med. 2012;156(2):105-114.

157. Rafiq R, Aleva FE, Schrumpf JA, et al. Prevention of exacerbations in patients with COPD and vitamin D deficiency through vitamin D supplementation (PRECOVID): a study protocol. BMC Pulm Med. 2015;15:106

158. Albouaini K, Andron M, Alahmar A, Egred M. $\beta$-Blockers use in patients with chronic obstructive pulmonary disease and concomitant cardiovascular conditions. Int J Chron Obstruct Pulmon Dis. 2007; 2(4):535-540.

159. Andell P, Erlinge D, Smith JG, et al. $\beta$-Blocker use and mortality in COPD patients after myocardial infarction: a Swedish nationwide observational study. J Am Heart Assoc. 2015;4(4):1-13.

160. Salpeter SR, Ormiston TM, Salpeter EE. Cardioselective $\beta$-blockers in patients with reactive airway disease: a meta-analysis. Ann Intern Med. 2002;137(9):715-725.

161. Bhatt SP, Wells JM, Kinney GL, et al. $\beta$-Blockers are associated with a reduction in COPD exacerbations. Thorax. 2016;71(1):8-14.

162. Shah T, Churpek MM, Coca PM, Konetzka RT. Understanding why patients with COPD get readmitted: a large national study to delineate the Medicare population for the readmissions penalty expansion. Chest. 2015;147(5):1219-1226.

163. Krishnan JA, Gussin HA, Prieto-Centurion V, Sullivan JL, Zaidi F, Thomashow BM. Integrating COPD into patient-centered hospital readmissions reduction programs. Chronic Obstr Pulm Dis. 2015; 2(1):70-80.
164. Prieto-Centurion V, Markos MA, Ramey NI, et al. Interventions to reduce rehospitalizations after chronic obstructive pulmonary disease exacerbations: a systematic review. Ann Am Thorac Soc. 2014;11(3): 417-424.

165. Davis KJ, Landis SH, Oh YM, et al. Continuing to Confront COPD International Physician Survey: physician knowledge and application of COPD management guidelines in 12 countries. Int J Chron Obstruct Pulmon Dis. 2015;10:39-55.

166. Glaab T, Banik N, Rutschmann OT, Wencker M. National survey of guideline-compliant COPD management among pneumologists and primary care physicians. COPD. 2006;3(3):141-148.

167. Lopez-Campos JL, Hartl S, Pozo-Rodriguez F, Roberts CM. Antibiotic prescription for COPD exacerbations admitted to hospital: European COPD audit. PLoS One. 2015;10(4):e0124374.

168. Mularski RA, Asch SM, Shrank WH, et al. The quality of obstructive lung disease care for adults in the United States as measured by adherence to recommended processes. Chest. 2006;130(6):1844-1850.

169. Mäkelä MJ, Backer V, Hedegaard M, Larsson K. Adherence to inhaled therapies, health outcomes and costs in patients with asthma and COPD. Respir Med. 2013;107(10):1481-1490.

170. Koehorst-ter Huurne K, Movig K, van der Valk P, van der Palen J, Brusse-Keizer M. Differences in adherence to common inhaled medications in COPD. COPD. 2015;12(6):643-648.
International Journal of COPD

\section{Publish your work in this journal}

The International Journal of COPD is an international, peer-reviewed journal of therapeutics and pharmacology focusing on concise rapid reporting of clinical studies and reviews in COPD. Special focus is given to the pathophysiological processes underlying the disease, intervention programs, patient focused education, and self management protocols.

\section{Dovepress}

This journal is indexed on PubMed Central, MedLine and CAS. The manuscript management system is completely online and includes a very quick and fair peer-review system, which is all easy to use. Visit $\mathrm{http}: / / \mathrm{www}$.dovepress.com/testimonials.php to read real quotes from published authors. 